\section{2a WORK-RELATED UPPER EXTREMITY MUSCULOSKELETAL DISORDERS IN ITALY}

FS Violante. Department of Medical and Surgical Sciences, University of Bologna, Italy

\subsection{6/oemed-2018-ICOHabstracts.727}

Upper extremity musculoskeletal disorders were scheduled as occupational disorders in Italy in 2008 (Decree of the Ministry of Labour, 9 April 2008). Compensable disorders now include tendonitis of the supraspinatus, long head of biceps, Duplay's disease, shoulder bursitis, lateral and medial elbow tendonitis, olecranon's bursitis, hand-wrist tendonitis, De Quervain syndrome and carpal tunnel syndrome. No guidelines on diagnosis are mandated by the regulation, but the process should rely upon consolidated medical practice. However, the regulation does specify the exposure conditions under which the disease can be considered of occupational origin, albeit in a very broad way, without any detail about how to assess the exposure and how to define a specific level for the exposure to be considered causal. Within the Italian Society of Occupational Medicine (SIML), a framework for assessing the quality of both the diagnostic criteria and the exposure is being developed. This framework will include a set of evidence based, minimum required exposures for considering a disease as likely occupationally induced. The new framework and detailed exposure criteria will be presented.

\section{$1632 \mathrm{~b}$ UPPER LIMB DISORDERS: THE UK PERSPECTIVE}

${ }^{1,2}$ Ira Madan, ${ }^{1,3}$ Karen Walker-Bone. ${ }^{1}$ Arthritis Research UKMRC Centre for Musculoskeletal Health and Work, Southampton University, UK; ${ }^{2}$ Guys and St Thomas' NHS Foundation Trust, London, UK; ${ }^{3} M R C$ Lifecourse Epidemiology Unit, Southampton University, UK

\subsection{6/oemed-2018-ICOHabstracts.728}

Since the early 1990s, the UK occupational health community has attempted to minimise the use of the term 'work-related' in the context of upper limb disorders (ULDs). Whilst acknowledging that symptoms can be caused, or made worse, by work, the tautology of the term has been thought unhelpful, particularly when carrying out epidemiological research. Our system of compensation for work-related injuries or diseases is called the Industrial Injuries Disablement Benefit (IIDB). Prescription is based upon recommendations from the independent Industrial Injuries Advisory Council. Currently, the only ULDs which are 'prescribed' are: task specific focal dystonia of the hand or forearm (writer's cramp); subcutaneous cellulitis of the hand; bursitis or subcutaneous cellulitis arising at or about the elbow due to severe or prolonged external friction or pressure at or about the elbow; tenosynovitis; vibration white finger; carpal tunnel syndrome and Dupuyten's contracture legislation is just passing through Parliament. These are however only prescribed in relation to strictly defined occupational exposures and awarded after consideration of the disablement caused. The case definitions and exposure assessment will be presented in detail.

Our group developed the Southampton examination proforma for epidemiological research into ULDs based upon the Harrington criteria in the late 1990s. The published validation of this proforma was used extensively in developing the Sluiter assessment criteria. Some of these data will also be shared.

\section{C CRITERIA FOR WORK-RELATED UPPER EXTREMITY MUSCULOSKELETAL DISORDERS IN FRANCE}

${ }^{1} \mathrm{~A}$ Descatha, ${ }^{2} \mathrm{~A}$ Petit, ${ }^{2} Y$ Roquelaure. ${ }^{1}$ AP-HP Univ Versailles St-Quentin INSERM, Garches, France; ${ }^{2}$ INSERM, University of Angers, Angers, France

\subsection{6/oemed-2018-ICOHabstracts. 729}

The definition of work-related musculoskeletal disorders in France depends on the context: the legal and social insurance for work compensation of such disorders has criteria for shoulder tendonitis, epicondylitis, bursitis, ulnar nerve syndrome at the elbow and at the wrist, wrist tendinopathies of the fingers (including DeQuervain's Disease), Carpal Tunnel Syndrome. These will be presented. However, the criteria are restrictive and may not be appropriate in an occupational setting for screening. The European guide is commonly used (Sluiter, 2001). ${ }^{1}$ For CTS and shoulder tendonitis, there are also general medical guidelines for diagnosis with specific investigations (nerve conduction studies and imaging respectively) and for treatment. In conclusion, several different criteria sets are available each with their strengths and limitations.

\section{REFERENCE}

1. Sluiter BJ, Rest KM, Frings-Dresen MH. Criteria document for evaluating the work-relatedness of upper-extremity musculoskeletal disorders. Scand I Work Environ Health 2001;27(Suppl 1):1-102.

\section{2d WORK-RELATED UPPER EXTREMITY MSDS IN GERMANY}

EB Ochsmann. Luebeck Institute of Occupational Health, University of Luebeck, Germany

\subsection{6/oemed-2018-ICOHabstracts.730}

There are currently four occupational musculoskeletal disorders of the upper-extremity in the Annex of the German Ordinance of Occupational Diseases. These are: diseases of tendons or tendon sheaths or tendon and muscle insertions (occupational disease no. 2101, 722 suspected cases in 2015), diseases caused by working with vibrating or pneumatic machines (occupational disease no. 2103, 423 suspected cases in 2015), pressure damages of nerves (occupational disease no. 2106, 98 suspected cases in 2015), and pressure damage of nervus medianus in the carpal tunnel caused by manual work with flexion and extension of the wrist, with increased hand force or with hand-arm-vibration (occupational disease no. 2113, 1.391 suspected cases in 2015). ${ }^{1}$ The oldest of these occupational diseases was introduced in 1963, the youngest in 2009. In Germany, there is a strong interest in the differentiation between 'occupational diseases' and 'diseases of the general population'. While the former are managed by the Statutory Accident Insurances, the latter are managed mostly by the Statutory Health Insurances. Therefore, for most of the occupational diseases there are defined occupational exposures or defined occupational groups. This presentation gives an overview about the current situation in a socio-legal context.

\section{REFERENCE}

1. DGUV (German Social Accident Insurance) DGUV Statistics 2015; http://www. dguv.de/medien/inhalt/zahlen/documents/dguvstatistiken2015e.pdf 